\title{
CONSTRUCTION OF SMART COMMUNITY BASED ON GIS AND TILT PHOTOGRAMMETRY
}

\author{
Dou Shiqing ${ }^{1}$, DING Shiyi ${ }^{2}$
}

1. College of Geomatic Engineering and Geoinformatics, Guilin University of Technology, Guilin 541004, China;

2. College of Mining Engineering, Heilongjiang university of science and technology, Harbin 150022, China

KEY WORDS: Smart community; Tilt photogrammetry; Monomer model; cesium.js; Vue.js; WeChat applet

\begin{abstract}
:
As a component of smart city, smart community is the community form in the information age. With people's higher pursuit of living environment, safety, convenience and other intelligent aspects, the construction of smart community continues to accelerate. However, there are still some problems such as uneven community safety management level, data island, insufficient quality service projects and lack of participation of residents. This paper studies and practices the construction of smart community based on GIS and tilt photogrammetry. The smart community uses tilt photogrammetry technology to restore the real scene of the community as the data source. The core work of field data acquisition, 3D model construction and monomer modelling of the real scene is carried out. Then, the smart community web terminal is built based on Cesium.js and Vue.js framework, and the mobile terminal is developed by using WeChat applet. The experiment shows that this system can build a communication bridge between managers and users, and it is convenient for property management personnel to carry out accurate positioning verification, inspection, maintenance and timely feedback of community events on the information reported by users in real time. The whole smart community system can provide intelligent and convenient conditions for residents of the community, It can improve the existing management level of the community and provide the valuable technical reference for the current construction of smart communities
\end{abstract}

\section{INTRODUCTION}

As a component of smart city, smart community is the community form in the information age. With people's higher pursuit of living environment, safety, convenience and other intelligent aspects, the construction of smart community continues to accelerate. Based on cloud technology, big data and other modern technologies, Smart community is equipped with relevant sensors ${ }^{[1]}$, and it takes population, legal person, spatial geography, economy and buildings as the basic data resources of smart community platform ${ }^{[2-4]}$. Smart community uses GIS technology, Internet and Internet of things to further improve the level of community public services ${ }^{[5]}$.

The research on smart communities in China has reached an international level. WU Shengwu proposed to integrate the Internet, medical care, property management, energy and other fields to build a convenient, efficient, environmentally friendly and sustainable smart community development model in $2003^{[6]}$. Starting from the process of community informatization, XIE Hua and GU Ying expounded several major elements of the transformation from the traditional community to the smart community ${ }^{[7]}$.

The state and local governments have also issued various programmatic documents on the construction of "smart communities". Smart community pilot projects are also underway across the country. For example, Shanghai attaches great importance to the construction of data service platform, focuses on the living needs of residents, and develops smart applications with community characteristics. Haishu wisdom community is committed to the comprehensive integration of regional government administration and public resources to provide efficient services for community residents in Ningbo, Zhejiang province ${ }^{[8]}$. However, due to the limitation of funds, scientific research and technology and actual 
residents' needs, the smart community system has the disadvantages of 'looking at the outside but not applying'. Community events cannot be quickly identified and solved in time, and residents' satisfaction with smart communities is insufficient ${ }^{[9]}$. Harbin city "Shimao Firenze" residential district is taken as a pilot, this paper explores the establishment of intelligent community based on GIS and tilt photogrammetry, and studies the approach of building a web side of smart community based on Cesium. Js and Vue. Js frameworks. It aims to build a wisdom of integrated residents and management services platform. community residents can enjoy convenient service, which can report by mobile phone, computer landing platform event information, and property managers can receive information on the incident point real-time monitoring and feedback to the community residents event handling process.

\section{TILT PHOTOGRAMMETRY AND 3D DATA} PROCESSING

\subsection{Field data acquisition for Tilt photogrammetry}

Tilt photogrammetry can obtain multidirectional photographs of areas of interest. In the case that the overlap degree and navigation height meet the ground resolution, tilt photogrammetry can extract feature points through aerial triangulation by beam method. In order to ensure the precision of the monomer model in later data processing meets the second-level model, the course planning and image control point layout should be designed in the field data acquisition stage of tilt photogrammetry.

The experimental area is the "Shimao Firenze " in Songbei district of Harbin city. In this experimental area, the environment is beautiful, the trees are luxuriant, but the shielding phenomenon is serious, so the course overlap degree and side overlap degree adopt $80 \%$ and $70 \%$ respectively. After field visit, the tallest building is less than 100 meters. According to table 1 , based on the relationship between mapping scale and ground resolution, the flight height is calculated by relying on ground resolution, the calculation formula is shown in equation 1-1.

$$
H=\frac{\mathrm{f}^{*} \mathrm{GSD}}{a}
$$

In this formula, the height of photography flight is $\mathrm{H}$; The ground resolution is GSD; The pixel size is a; The focal length of the objective lens is f. In this paper, GSD was selected as $2 \mathrm{~cm}$, and the height was selected as $180 \mathrm{~m}$ according to the experience.

Tab.1 The comparison of surveying scale and ground resolution

\begin{tabular}{cl}
\hline Surveying and mapping scale & Ground resolution/cm \\
\hline $1: 500$ & $\leq_{5}$ \\
\hline $1: 10$ & $8 \sim 10$ \\
\hline $1: 2000$ & $15 \sim 20$
\end{tabular}

Since the experimental area is a plain area and the ground features are clearly distinguished, the post-processing software can carry out encryption control points through air triangulation by beam method. Therefore, this project used the regional network method to conduct image control points layout. The layout principle is:

1)As far as possible, the control points are arranged on such hard-edged ground objects as manhole cover and zebra crossing corner points. If ground objects are difficult to distinguish, we can use paint and prepare L-shaped hollow cardboard boxes to make an L-shaped shape on the ground.
2)The image control points are mainly arranged at the corner points of the region. In practice, the control points will be offset and rearranged due to special situations such as water surface.

3)In order to facilitate RTK to measure the coordinates of image control points, places with good GPS signals should be selected, but it should be far away from signal towers, houses and trees as far as possible.

Route planning and image control point layout are shown in figure 1. 


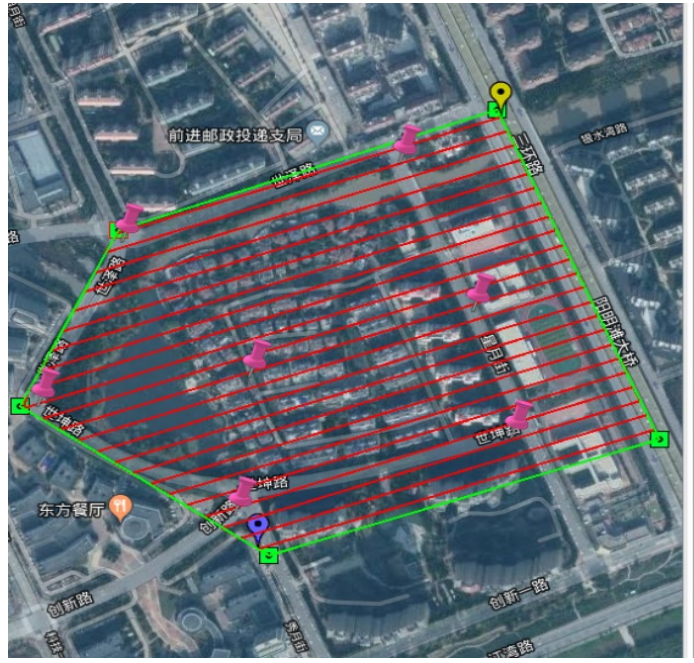

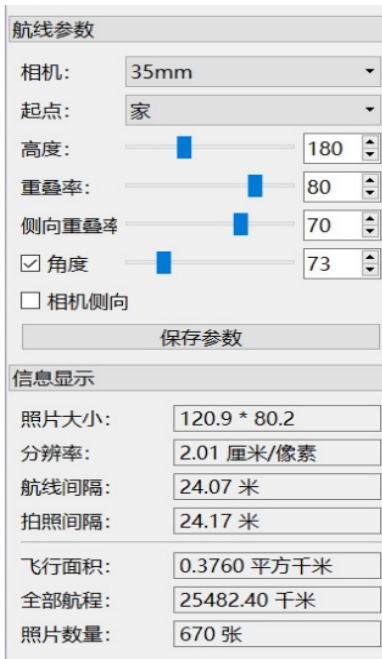

Fig.1 Route planning and image control point layout

\section{2 real scene 3D model}

The real scene 3D model is completed by using the modelling software (ContextCapture). Compared with traditional 3DMax modeling, this method has fast efficiency, high precision and low working intensity ${ }^{[10]}$. By matching and mapping the tilted photos and image control points, the feature points proposed by aerial triangulation constitute point cloud. By thinning the dense point cloud, the adjacent feature points in the point cloud are connected into TIN to form a triangular network surface. The plane connected by feature points corresponds to the plane of the photo, and the texture of the inclined photo is assigned to the plane of feature points.

Considering the large storage capacity of the point cloud generated by aerial triangulation, and the operation memory of the computer is required during the generation of the real scene 3D model. A workstation is used for data processing. The running memory is $32 \mathrm{G}$, and the model is set to $60 \times 60$ meters after being partitioned by plane rules. The RAM required by the model is $8 \mathrm{G}$. The 13 machines in the local area network are built into a cluster to jointly produce the real scene 3D model. The final three-dimensional panoramic image of the community is shown in fig. 2 .

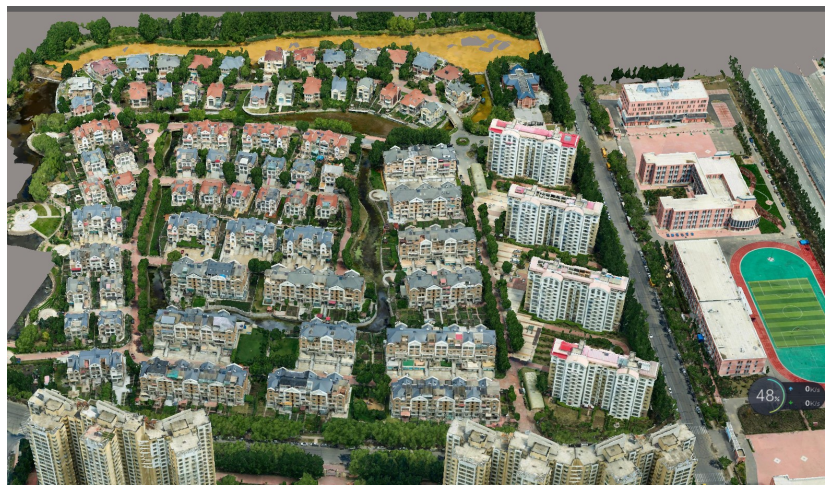

Fig.2 Real 3D panorama of the community

\subsection{Monomer Modelling}

The realistic 3D model generated by ContextCapture is a continuous triangular network, which cannot distinguish buildings, trees, ground, etc., and there is the phenomenon of "one skin". Based on the above reasons, if $3 \mathrm{D}$ model is to be applied in the development of intelligent community GIS, it needs to carry monomer modeling operation. SVS Modeler is a monomer modeling software launched by Wuhan 
Smart Vision Space co., LTD. Compared with traditional manual modeling, this method has higher precision and faster modeling. The monomer model directly replaces the original model, which improves the display effect and realizes the real monomer.

Based on the modeling of the main body, such as roof and wall, the monomer model is divided into four levels according to whether the building details need to be modeled, including plane, concave and convex length, plane position error with the actual object, height difference and the number of individual model faces. The required technical parameters for modeling at all levels are shown in tab.2, and the models at all levels are shown in fig.3.

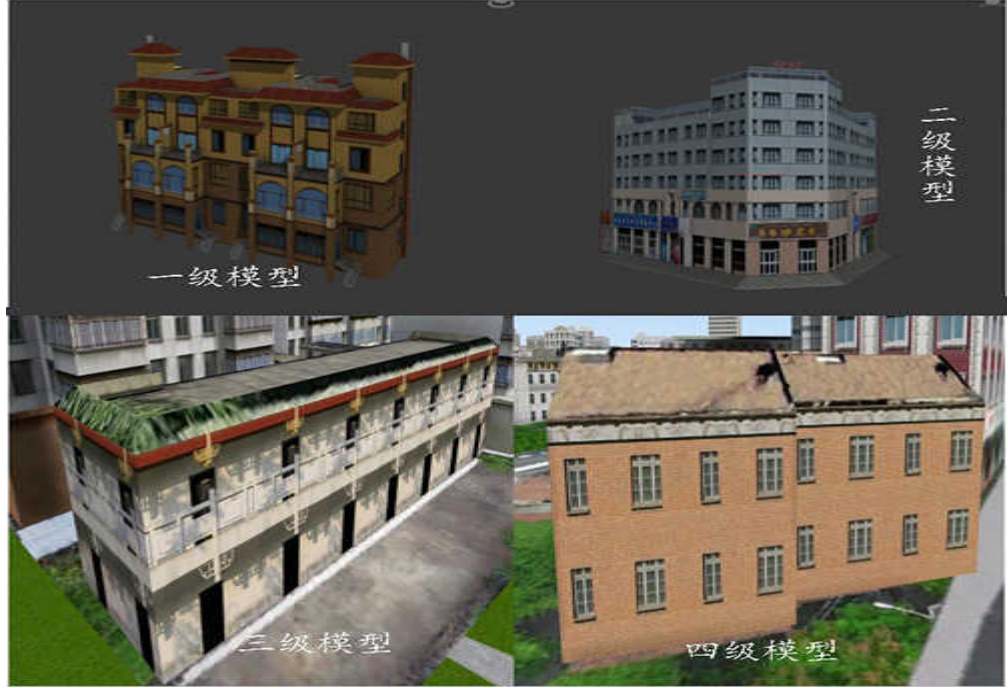

Fig. 3 Comparison of models at all levels

Tab.2 Standards for modeling technical parameters

\begin{tabular}{lcccc}
\hline & $\begin{array}{c}\text { Modeling of plane and } \\
\text { concave-convex structure } \\
\text { features }(\mathrm{m})\end{array}$ & $\begin{array}{c}\text { Plane position } \\
\text { error } \\
(\mathrm{m})\end{array}$ & $\begin{array}{c}\text { Height } \\
\text { difference } \\
(\mathrm{m})\end{array}$ & $\begin{array}{c}\text { Number of model } \\
\text { construction surfaces }\end{array}$ \\
\hline Level 1 model & $\geq 0.5$ & $\leq 0.6$ & $\leq 0.8$ & $\leq 6000$ \\
\hline Level 2 model & $\geq 1$ & $\leq 0.6$ & $\leq 0.8$ & $\leq 3000$ \\
\hline Level 3 model & $\geq 1.5$ & $\leq 1$ & $\leq 1.5$ & $\leq 1500$ \\
\hline Level 4 model & $\geq 2$ & $\leq 2$ & $\leq 1.5$ & $\leq 500$
\end{tabular}

\subsection{Model format conversion}

Cesiun is an open source Javascript library for map rendering using Web GL. Cesium library supports the 3D tile import of 3D models in GLTF, GLB and dae formats ${ }^{[11]}$. We need to convert the OSGB format single model file into OBJ format, and then use GLTF conversion tool to make the model into GLTF format. By importing the monomer model into Cesium, you can conduct web side development by connecting node. The attribute information of the model is stored in MongoDB in the form of text, which is mainly in Grid FS format.

\section{THE DESIGN OF THE INTELLIGENT COMMUNITY SYSTEM}

\subsection{The overall design}

Intelligent community system adopts the Browser/Server structure, by merchants, property management, residents as a major player. With the real $3 \mathrm{D}$ model as the underlying data, the system is designed for the participants, the presentation layer, support layer, data layer, network layer, five levels by the web front end development technology and database, and the support layer is the core of the system. The logical structure of the system platform is shown in fig.4. 


\begin{tabular}{|c|c|c|c|c|}
\hline \multicolumn{2}{|c|}{ 参与者 } & 离家 & An & $\begin{array}{l}\text { funin } \\
\text { 居民. }\end{array}$ \\
\hline \multirow{2}{*}{\multicolumn{2}{|c|}{ 表现层 }} & 国 & (c) & 5 \\
\hline & & 移动设备 & 互联刚设备 & 监控设备 \\
\hline \multirow{4}{*}{$\begin{array}{l}\text { 支 } \\
\text { 撑 } \\
\text { 层 }\end{array}$} & 社区刘刘筐 & 人品管理 & 数据标准接口 & \\
\hline & 建言的策 & 生活服客 & 数捛应用接口 & \\
\hline & 政务服客 & 空间㗐测 & 访问权限控制 & \\
\hline & \multicolumn{2}{|c|}{ 功能模块 } & 公用模块 & \\
\hline \multirow{2}{*}{\multicolumn{2}{|c|}{ 数据层 }} & sestitivi & & $\equiv$ \\
\hline & & 三维模型 & & 模型属性 \\
\hline \multicolumn{2}{|c|}{ 网络层 } & 正联网了 & & 物联网 \\
\hline
\end{tabular}

Fig.4 The logical structure of the system platform

As the support of the whole system, the network layer mainly includes the network environment, system organization and communication link created by the Internet and the Internet of things ${ }^{[12]}$.

The data layer consists of two parts: 3D model data and attribute data. 3D model data refers to the monomer model and 2D map data built from the 3D model of tilt photogrammetry. Attribute data are GIS attributes attached to the 3D model, such as household name, family member, family address, remarks, etc.

The support layer is the service support environment of the system, which is mainly divided into user-oriented function module and developer-oriented public module. The function module relies on the service functions designed by the demand analysis in the early stage of system construction. The public module is the interface reserved for each service function in the whole system development process, which is convenient to increase and improve functions over time.

\subsection{Database design}

The intelligent community system adopts MongoDB database. All of Mongo DB's data is stored in the cache, which is much faster to query than a relational database stored on the hard disk ${ }^{[13-15]}$. The model properties file is entered into the database in the canonical form of GridFS file. Each file will store a metadata object in the file collection object, and the large file will be split into several smaller documents through JSON format, it can increase the query speed.

\subsection{Functional design}

The support layer designs corresponding functions according to the needs of users, which are divided into six categories: community browsing, personnel management, Suggestions and Suggestions, life service, government service and space measurement. The community browsing function views the three-dimensional model of the community through zooming and roaming in the form of first-person perspective. The smart community platform sets up a life service window, and users can jump to obtain logistics services, housing rental, housekeeping and other needs by clicking enter. The government service function is connected with the page of Harbin municipal people's government. Users can directly obtain official and authoritative government services, such as marriage registration and personal entrepreneurship and so on. Users can express their opinions to the government in the public discussion, or directly express their opinions and report community events to the managers in the community platform. The managers can give feedbacks to the users based on the on-site investigation of the users.

Due to privacy concerns, the information of community residents can only be viewed in the community platform after the administrator has obtained permission. For example, civil servants such as police and regulatory authorities can search for names on the platform when they are required to check government documents, the 3D model will display a bulletin board to show civil servants the location of people's names, residential buildings, household population and special notes. The 3D model can also be used for measurement, which facilitates the acquisition of geographic location information. 


\section{INTELLIGENT COMMUNITY SYSTEM IMPLEMENTATIONS}

The functions of smart community platform are divided into managers and residents. The functions of managers are mainly personnel management, while the functions of residents are suggestions, life service, government affairs service and space measurement and so on

\subsection{Management function}

The system calls the $3 \mathrm{~d}$ model and model property file through the back-end database and Cesium interface, so as to provide ultra-fine $3 \mathrm{~d}$ model and other data services. The grid member can search through the personnel management after obtaining the authority. When the name of the person to be searched is output, the platform will automatically lock the building model that the person belongs to and display the property information of this model on the model, including name, address, housing area and remarks. Remarks mainly include special situations in the family, such as the elderly, the disabled, drug addicts, and persons with criminal convictions, etc., through which the manager is reminded to pay attention to the situation and better serve the community residents. If the community resident user information has changes, the manager can directly go into the database to update the document for adding, deleting and checking. Personnel management is shown in figure 6.

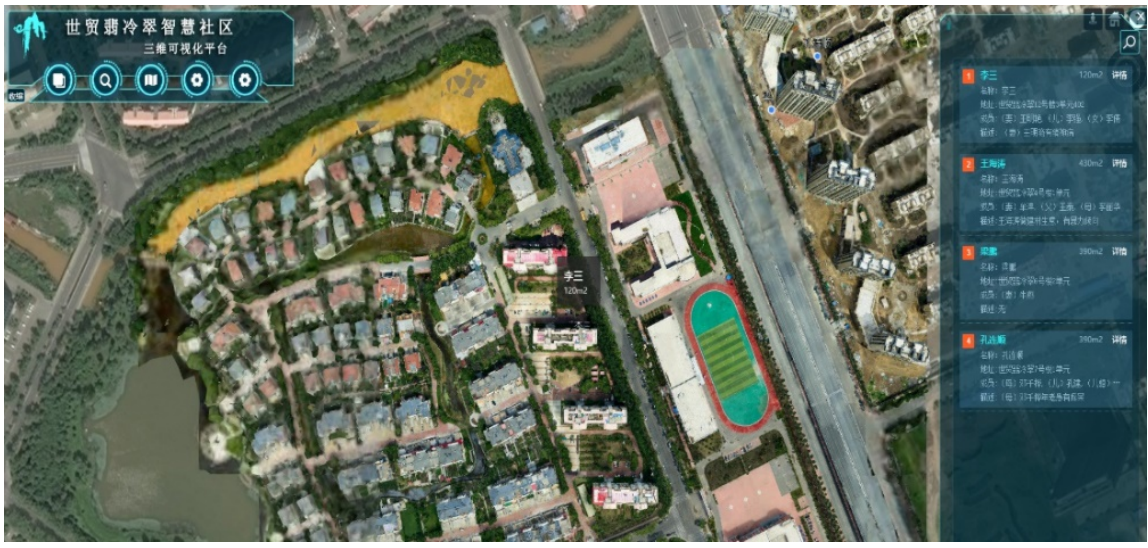

Fig. 6 people management function

\subsection{User function}

The life service window of smart community platform (as shown in fig. 7) provides users with home maintenance, life distribution, housekeeping, ticket office and other life services. Users only need to register to find the services that meet their needs through the link. The government service window is linked with the official website of Harbin municipal people's government, and all government affairs needs are handled according to this notice.

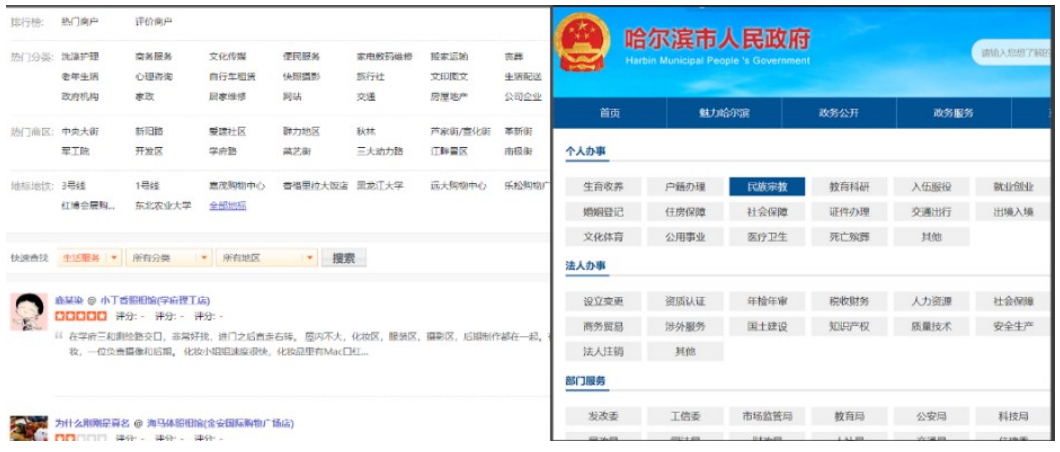

Fig.7 Life service and government service

If users find abnormal conditions in the community, they can directly obtain the local coordinates through the three-dimensional model on the platform of smart community, and fill in the report contents in the 
advice and suggestion window (as shown in fig.8). In order to enhance the accuracy of event reporting, users can obtain the specific spatial information of the event location through the measurement function and report it to the administrator, so that the administrator can accurately locate the event location.

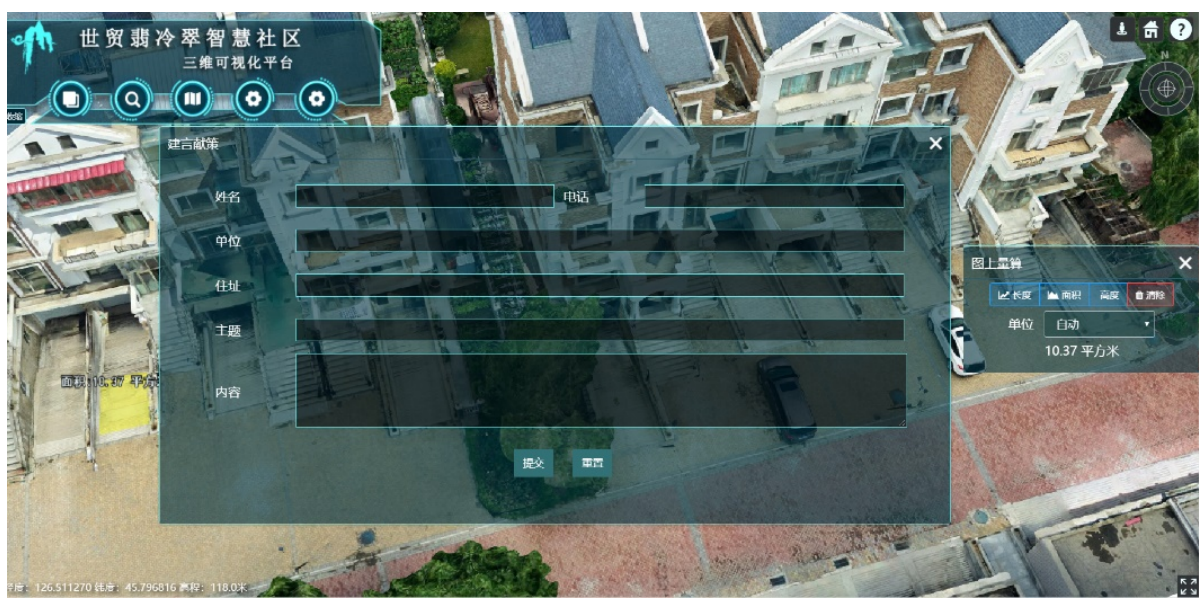

Fig.8 Suggestion

\section{CONCLUSION}

This intelligent community system aims to serve the life of community residents, and adopts modern equipment and web development technology to build the system. The system can meet the manager's precise positioning management of the community, and also build a bridge between residents and managers, which has certain reference significance for the construction of smart community. However, due to the limited practical conditions, it is impossible to combine the monitoring system with the smart community system. We hope to overcome this difficulty in the future development. Through the system construction of smart communities, the law of community development is deeply studied, and abundant relevant construction theories are obtained. It is a meaningful exploration of the theory of smart city construction, and has certain theoretical and practical significance for the construction of smart communities.

\section{REFERENCE}

[1] KANG Chun-peng. The Construction of Intelligence Community and Its Application in Social Management[J]. JOURNAL OF BEIJING YOUTH POLITICS COLLEGE,2012,21(02):72-76.

[2] LI Deren, YAO Yuan SHAO Zhenfeng. Big Data in Smart City[J].Geomatics and Information Science of Wuhan University, 2014,(39)06,631-640.

[3] LI Zonghua, PENG Mingjun, PAN Chenling. Construction of social management innovation platform based on spatiotemporal big data[J]. GEOSPATIAL INFORMATION,2016,14(9):1-6.

[4] LIU Dan, PEI Ying, LI Chuang. Research on the Establishment of Grid-based Intelligent Community Synergistic Service Platform[J]. Bulletin of surveying and mapping,2015(12):98-100.

[5] WANG Wei, LI Chengren, XU Shuying. Intelligent community management system based on 2D and 3D GIS[J].

GEOSPATIAL INFORMATION,2017,15(07):6-9.

[6] WU Shengwu. Some thoughts on the construction of smart community[J]. Sanjiang forum,2013(3):7-10.

[7] XU Yizhi. Research on Technologies of spatiotemporal data pulsation analysis based on GIS platform[D].Hefei: The University of Chinese Academy of Sciences,2017.05.

[8] LIU Quanhai, RAN Huimin, LI Lou, et al. With the wisdom planning of space-time information intelligent collection platform construction $[\mathrm{J}]$. Technology Geographic Information, 2015(06):64-67. [9] FANG Shuguang. The Government Leading, Wisdom: Innovation Research of Central City Community Construction[J]. JOURNAL OF NANYANG INSTITUTE OF TECHNOLOGY,2014, (05):12-16. 
[10] XU Wenwu. Design and Development of Three Dimensional Intelligent Community Management System Based on GIS[J]. Beijing Surveying and Mapping,2016(06):65-68.

[11] WANG Yikai, XU Meng, LUO Jiansong, WANG Lin. Implement of Web GIS System Based on Cesium[J]. GEOMATICS \&SPATIAL INFORNATION

TECHNOLOGY,2019,42(04):88-89.

[12] GAO Wenjua, CHEN Ye, GONG Bing.et.al.
Research on Establishing an Application Platform for a 3D GIS Smart Community Based on RFID.

[13] YANG Peng, LIN Junhui. A Scheme for Massive Unstructured mass data Processing Based on MongoDB and Hadoop[J]. MICROELECTRONICS \&COMPUTER,2018,35(04):68-72+78.

[14] K. Banker. Mongo DB in action[M]. Manning Publications Co,2011:15-17.

[15] K. Chodorow, M. Dirolf. MongoDB: the difinitive guide[M]. O Reilly Media,2010:72-75. 